\title{
SEA-BOTTOM SHEAR-WAVE VELOCITIES AND MODE CONVERSIONS
}

\author{
Carlos Rodriguez-Suarez
}

Recebido em 20 abril, 2005 / Aceito em 20 julho, 2005

Received on April 20, 2005 / Accepted on July 20, 2005

\begin{abstract}
Elastic parameters for shallow marine sediments were obtained from the literature (Hamilton (1976,1979); Hovem et al. (1991); Esteves (1996)) and previously unpublished geotechnical data from offshore Brazil. The Brazilian data showed reasonable agreement with Hamilton's results except in the very shallow (above $10 \mathrm{~m}$ ) sedimentary section. A second order equation to calculate VS as a function of depth in marine sediments is derived empirically down to a depth of $140 \mathrm{~m}$. Analyses of transmission and reflection coefficients for compressional- and shear-wave energy mode conversion using Zoeppritz equations were performed for both the sea bottom and a typical hydrocarbon reservoir top of Tertiary age. It is concluded that most S-wave reflection data recorded on the ocean floor by OBC is related to upcoming energy converted at an interface at depth and not from a downgoing shear conversion at the ocean floor.

It was also concluded that, using elastic assumptions, mode conversion (both P- to S- and S- to P-) of the up going energy is negligible in the shallow (above $160 \mathrm{~m}$ ) sediments.
\end{abstract}

Keywords: $V_{S}$ in marine sediments, mode conversion.

RESUMO. Parâmetros elásticos para sedimentos marinhos rasos foram obtidos de literatura (Hamilton (1976,1979); Hovem et al. (1991); Esteves (1996)) e dados geotécnicos marítimos inéditos do Brasil. Os dados brasileiros mostraram uma correlação razoável com os resultados de Hamilton exceto para a seção sedimentar muito rasa (acima de $10 \mathrm{~m}$ ). Uma equação de segunda ordem para calcular $\mathrm{V}_{\mathrm{S}}$ como função de profundidade foi derivada empiricamente até uma profundidade de $140 \mathrm{~m}$. Análises de coeficientes de transmissão e reflexão para conversão de modo em ondas compressionais e cisalhantes usando equações de Zoeppritz foram realizadas para o fundo do mar e um topo de reservatório de idade Terciária típico. Conclui-se que a maior parte das ondas-S refletidas e registradas no fundo do mar por cabos de fundo oceânico está relacionada à energia ascendente convertida em uma interface profunda e não de uma onda-S descendente convertida no fundo do mar. Foi concluído também que, usando premissas elásticas, a conversão de modo (tanto P- para S- quanto S- para P-) da energia ascendente é negligenciável nos sedimentos rasos (acima de $160 \mathrm{~m}$ ).

Palavras-chave: $V_{S}$ em sedimentos marinhos, conversões de modo. 


\section{INTRODUCTION}

Analyses of marine seismic data acquired using the ocean bottom cable $(\mathrm{OBC})$ technique generally require some knowledge of the physical properties of marine sediments. The shallow sedimentary section may be especially important, as dramatic changes in elastic parameters are common over small distances. This may affect various algorithms, as for example, P-P and P-S wave separation, static corrections, and velocity analysis.

In this work, a study of the energy mode conversion for the down going seismic energy that occurs at the sea floor and a comparison with reflected conversions at a representative interface of Tertiary sediments is presented.

To verify if the presence of $S$-waves in the vertical component (and P-wave in horizontal) could be due to mode conversion close to the receivers, conversion for the up-going seismic energy in the shallow sediments was also analyzed.

\section{PHYSICAL PROPERTIES OF MARINE SEDIMENTS: OVERVIEW OF LITERATURE DATA}

Hamilton (1976; 1979) made some of the first analyses on S-wave velocity in marine sediments. In the earlier paper, he obtained empirically the expressions

$$
V_{S}=128 z^{0.28}
$$

( $z$ depth in meters) for sands and

$$
V_{S}=116+4.65 z
$$

for silt clays. In the second, he found an empirical relation between $V_{p}$ and $V_{S}$ (and $V_{p} N_{S}$ values) for marine sediments. In both articles he used in-situ measurements data from different geographical locations, water depths and lithologies.

For siliciclastic sediments, he found $V_{P} / N_{S}$ ratios of around 13 for shallow sediments, decreasing to around 2.6 at a $1 \mathrm{~km}$ depth. For sands, $V_{p} N_{S}$ ratios have high gradients in the first meters, from around nine at $5 \mathrm{~m}$ and decreasing to six at $20 \mathrm{~m}$. He had no measurements for unconsolidated or soft limestones. As a final remark, he reiterated that very shallow sediments might have very high $V_{P} / N_{S}$ ratios. He reports a value of 46 , and believed that even higher values may be found.

One may guess his hypothesis of very high values for $V_{P} N_{S}$ ratios is possible when the porosity goes over $60 \%$, as the material then is not an unconsolidated sediment anymore, but instead, a suspension of grains in salty water (Nur, 1993) - in this case, $V_{S}$ approaches zero.

It should be pointed that, although Hamilton expected very low $V_{S}$ values in very shallow (above $10 \mathrm{~m}$ ) marine sediments, the use of his equations ( 1 and 2 ) gives values consistently higher than what is measured in sediments (Richart et al. (1970); Breeding et al. (1991); Lavoie and Anderson (1991); Figure 4). This may be due to rapid vertical changes in physical properties of these sediments regarding shear-wave propagation, not considered is his empirical derivations. For these sediments, Breeding et al. (1991), Briggs (1991) and Richardson et al. (1991) report Biot (1956a; 1956b) poroelastic and Bryan and Stoll (1988) models to have better agreement with measurements.

Hamilton results are shown in Figure 1.

Richardson et al. (1991), analyzing the upper $2 \mathrm{~m}$ of sediments in shallow water, conclude that the shear modulus is controlled by consolidation for sands, but for fine-grained sediments, other processes are important. According to the authors, values predicted by Hamilton (1976), and Bryan and Stoll (1988) near the sea bottom are often higher than measured values.

Theilen \& Pecher (1991), using cores analyzes and in-situ measurements from the upper nine meters of sediments in the Barents Sea, found small variation on $V_{p}$ but a rapid increase (from 10 to $40 \mathrm{~m} / \mathrm{s}$ ) on $V_{S}$.

Duennebier \& Sutton (1995) consider a value of $20 \mathrm{~m} / \mathrm{s}$ appropriate for high-porosity shallow marine sediments in ocean bottom seismometers (OBS) coupling problem analysis. They relate values varying between 10 and $40 \mathrm{~m} / \mathrm{s}$ from the literature.

Ayres \& Theilen (1999) present data for near-surface sediments (upper $9 \mathrm{~m}$ ) from the continental slope of the Barents Sea. S-wave velocities are much more sensitive to lithology changes than P-wave (which have a narrow range of velocity values). Most of the floor of the Barents Sea continental slope is covered by sandy clays, marls and oozes. The sediments have unexpected over-consolidation in the upper meter. $V_{S}$ varies between $9 \mathrm{~m} / \mathrm{s}$ and $47 \mathrm{~m} / \mathrm{s}$.

\section{SHEAR-WAVE VELOCITIES FROM OFFSHORE BRAZIL: DIRECT MEASUREMENTS AND GEOTECHNICAL DATA}

The values used in this section to obtain elastic parameter came from direct $\mathrm{V}_{S}$ measurements in the shallow sediments and geotechnical data, both obtained offshore Brazil.

The data were acquired at water depth ranging from 20 to 2,000 $\mathrm{m}$ and on lithology composition varying from sand to shales and oozes to limestones. Depths from zero to $132 \mathrm{~m}$ below the sea floor were analyzed on 30 different locations.

The direct $V_{S}$ measurements used the seismic cone penetrometer technique, a small VSP-like survey. In this survey, it is possible to combine standard geotechnical tests with in-situ $V_{S}$ mea- 

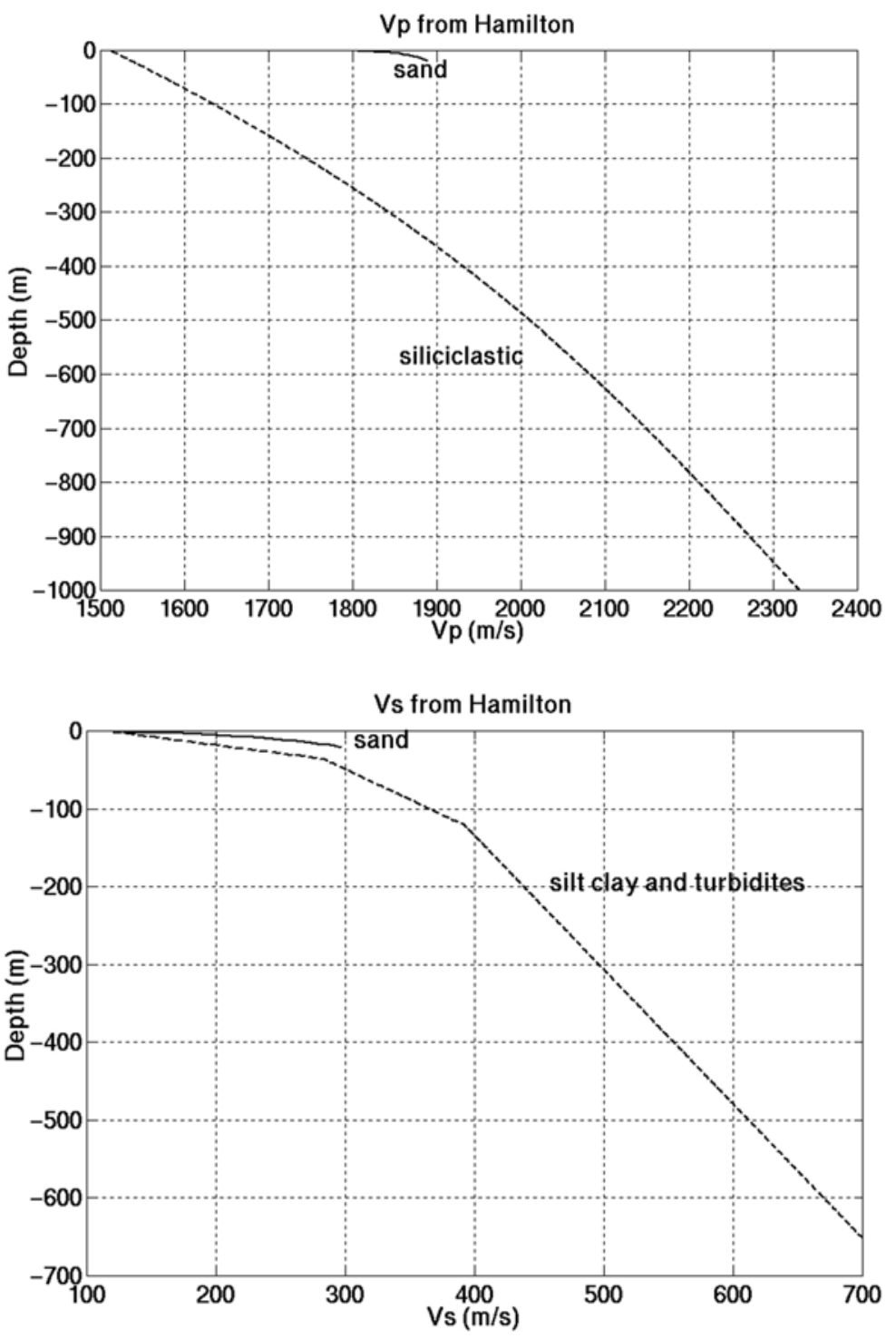

Figure 1 - Top: Vp values for marine sediments from Hamilton (1976; 1979). Observe distinct curves for siliciclastic and sand lithologies. Bottom: $V_{S}$ values for marine sediments from Hamilton $(1976 ; 1979)$. Unlike $V_{P}$, the curves for different lithologies are similar. All curves from in-situ measurements.

surements in the same acquisition. Shear-waves, generated in the sea floor by a hydraulic driven spring hammer, are recorded by two orthogonal geophones, mounted horizontally in a piezocone penetrometer. Responses from both geophones are considered in velocity calculation. An umbilical cable connects the geophones to a seismograph. In general, the shear-wave source is activated several times for a constant geophone depth, to increase signal to noise ratio. Interval velocities are obtained directly between two successive measurement depths. An acquisition scheme is shown in Figure 2. More information about this technique can be found in Robertson et al. (1986) and de Lange (1991).

In the Brazilian data, velocity measurements were obtained at approximately every 5 meters. Cone penetrometer surveys were performed in six different locations over distinct Brazilian offshore oil and gas fields.

The geotechnical data were acquired to support analysis of offshore installations (drilling and production platforms and pipelines) on the sea bottom. Pure geotechnical data (without $V_{S}$ measurements) from 26 locations, also over Brazilian oil and gas offshore fields, were also used in the analyses presented here. 


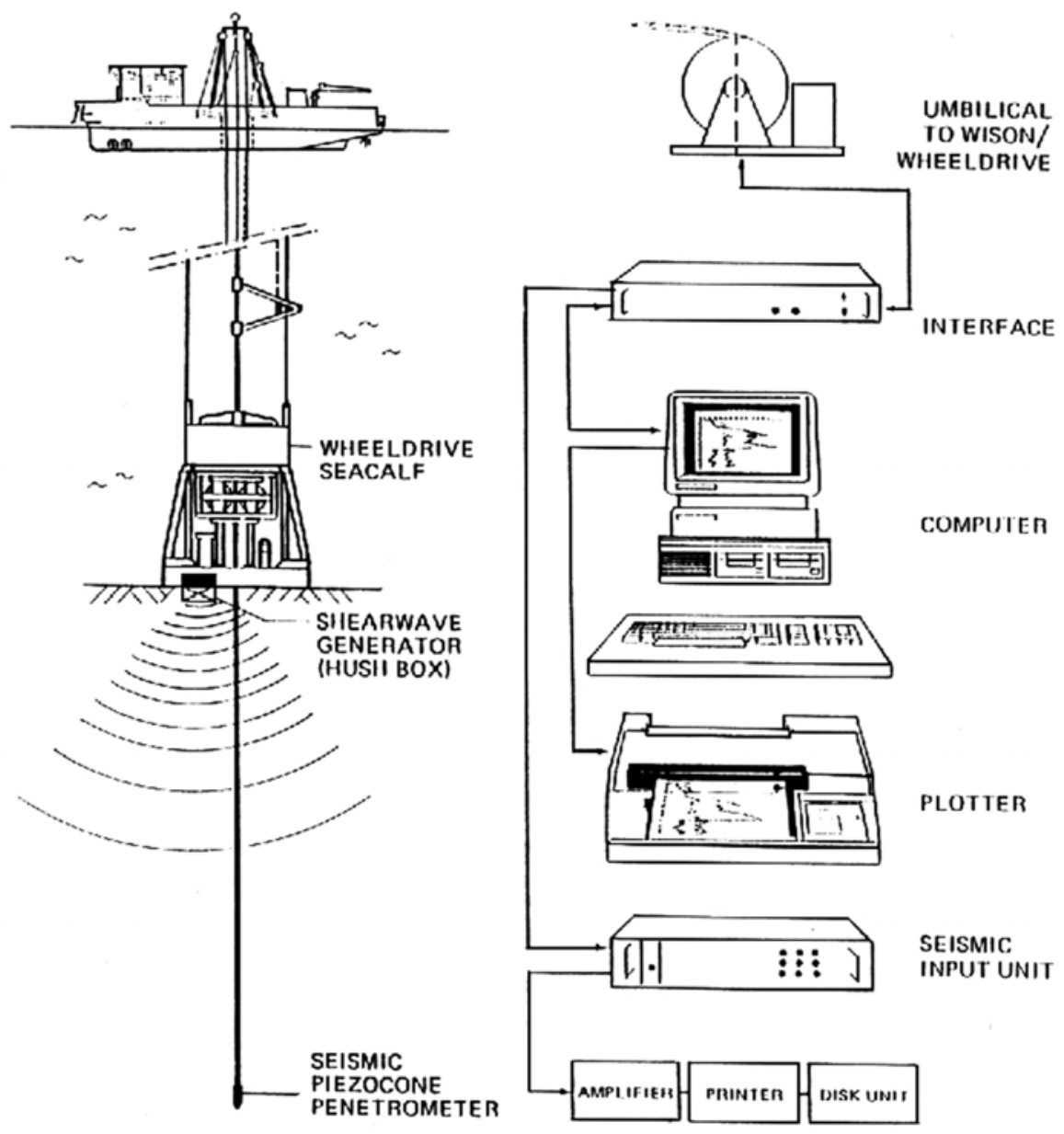

Figure 2 - Offshore acquisition of conventional geotechnical and VS information (from de Lange, 1991).

The shear modules from the pure geotechnical surveys were obtained in the laboratory with the original fluids in the sediment (Kubena and Post, 1992). Density information was available in all 30 locations.

In other to use pure geotechnical information as a source of shear-wave velocity, it is necessary to establish a correlation between the 'geotechnical' shear modulus (also called shear strength, or $\mathrm{S}_{U}$ ) and the 'dynamic shear modulus', or Lame's constant, $\mu$. The dynamic shear modulus defines shear-wave velocity according to the well-known expression

$$
V_{S}=\sqrt{\mu / \rho},
$$

$\rho$ density.

The dynamic modulus derivation is based on very small strain (less than $10^{-6}$ ) and a linear stress-strain regime (Hooke's Law is valid) (Macelwane and Sohon, 1936; Muskhelishvili, 1963; Sheriff and Geldart, 1995). Geotechnical (or engineer) modulus, however, in general is related to the material break point, involving much larger strains, where Hooke's Law may not be applicable (strain-stress relation is not linear anymore).

Nevertheless, some relation between the two parameters is intuitively expected. Richart (1975), based on land data, found that $V_{S}$ measurements in-situ could be used as an indication for $S_{u}$. Some published discussions about this correlation are presented below. In general, the authors are interested in the opposite problem - to obtain geotechnical parameters from seismic measurements.

Theilen \& Pecher (1991), analyzing cores from the upper nine meters of sediments in the Barents Sea, found a linear correlation on in-situ estimations of geotechnical and dynamic modulus the dynamic being around 200 times higher than the geotechnical. The authors believe specific correlation may be obtained for distinct kinds of sediments.

Baldwin et al. (1991) also obtained $S_{U}$ and $V_{S}$ (using a 1500 
$\mathrm{Hz}$ signal) for the same samples of marine clays from the Canadian Beaufort Sea (50 m water depth) and Portsmouth (NH). Unlike the data presented here, his measurements were not in-situ. They also found linear relation between $S_{u}$ and $V_{S}$, but by a factor which was a function of sediment consolidation.

In the data presented here, depth-variant correlation factors were obtained by averaging information from the six locations where both $\mathrm{S}_{U}$ and $\mathrm{V}_{S}$ were acquired. These factors $f$ were calculated simply by the expression

$$
f=\mu / S_{U}
$$

The results, shown in Figure 3, were applied to the remaining 24 locations where only $S_{u}$ was available. The picture shows that shear strength decreases remarkably for very shallow sediments, which would be intuitively expected. It also shows the value of 200 obtained by Theilen and Pecher (1991) occurs here around $10 \mathrm{~m}$, being higher for shallower sediments.

Using the correlation factor, $V_{S}$ profiles were calculated for the remaining 24 locations where only pure geotechnical data was acquired. The velocities values obtained from averaging $V_{S}$ from all 30 locations are presented on Figure 4. Also shown, for comparison, are the values expected from Hamilton expressions (equations 1 and 2).

In general, there is a reasonable agreement between Brazilian sediments and Hamilton results. The most remarkable discrepancies are around $40 \mathrm{~m}$ and in the very shallow (above $10 \mathrm{~m}$ ) section. The $40 \mathrm{~m}$ depth coincides with slope change on Hamilton curves, indicating that he probably consider some boundary should occur at this depth. Regarding sediments above $10 \mathrm{~m}$, it has already been mentioned that values from Hamilton expression are higher than what is generally found in the literature. Simple inspection of equations (1) and (2) indicates that, immediately below the sea floor, Hamilton expect $V_{S}$ over $100 \mathrm{~m} / \mathrm{s}$, what hardly has been observed in common marine sediments.

Using the measurements from all 30 locations, an empirical best fit second-order equation was obtained. It should be stressed that this equation is very general, and does not consider aspects that may be important, as lithology, consolidation, water depth and so on. Nevertheless, this equation can probably be used as first guess for VS in marine sediments when no other information is available. This may be especially true for geological environments similar to offshore Brazil - namely, extensional marine basins younger than Jurassic.

The empirical equation is ( $Z$ depth in meters).

$$
V_{S}=91.68+4.46 \cdot Z-0.017 \cdot Z^{2},
$$

\section{MODE CONVERSION FOR DOWN- AND UP-GOING WAVEFIELDS}

P-S mode conversion at the sea bottom may be important for hard bottoms (Tatham and McCormack, 1991), as the critical angle for the P-wave can be relatively small, generating most downgoing energy as S-waves. For instance, Tatham and Stoffa (1976) present some examples of conversion at the sea bottom, for shallow sediments with P-wave velocities over $2000 \mathrm{~m} / \mathrm{s}$.

According to Amundsen et al. (1999), the most important elastic parameter for the PSSP mode (P converting to downgoing $S$, reflecting as upcoming $S$ and converting back to $P$ at the sea bottom) is the $S$ velocity just below sea bottom. As an example, the authors say that if a Vp/Ns ratio equal or lower than 3.0 occurs in these sediments, PSSP amplitudes are comparable to PP reflection amplitudes.

However, it has been presented in this paper that almost all measurements presented in the literature (e.g. Hovem et al. 1991), at different locations, lithologies and water depths around the world, show that $V_{P} N_{S}$ is usually over 5.0 .

Besides, most reports on $\mathrm{OBC}$ data processing conclude that S-wave energy recorded at sea bottom is generated from P-to-S conversion at layer interfaces rather than at the sea bottom. In general, this conclusion came from moveout velocity analysis (the velocities are much higher than expected from pure S-S mode) and/or poor imaging when conventional CMP processing is applied to horizontal geophone components.

The comments above indicate that most shear wave energy recorded on the sea bottom is related to upcoming P-S conversions from deeper sediment interfaces, not downgoing conversions at the sea bottom. If this is true, in the absence of efficient, environmental friendly and economic ocean-bottom shear sources, we are called upon to analyze P-S reflection data.

For these reasons, converted-wave algorithms - S-wave receiver statics, P-S velocity analysis, P-S DMO, P-S imaging, etc. - have to be used.

Mode conversion at the sea bottom and at a typical top Tertiary reservoir interface were analyzed and compared using the Zoeppritz equations coded in Matlab by Prof. Gary Margrave (CREWES/University of Calgary).

The near-surface sediments elastic parameters were obtained by averaging the data from Hamilton (1976; 1979), Baldwin et al. (1991), Breeding et al. (1991), Briggs (1991), Lavoie and Anderson (1991), Richardson et al. (1991), Theilen and Pecher (1991), Duennebier and Sutton (1995), Esteves (1996), Ayres and Theilen (1999) and Brazilian offshore data presented on Figure 4 (compi- 


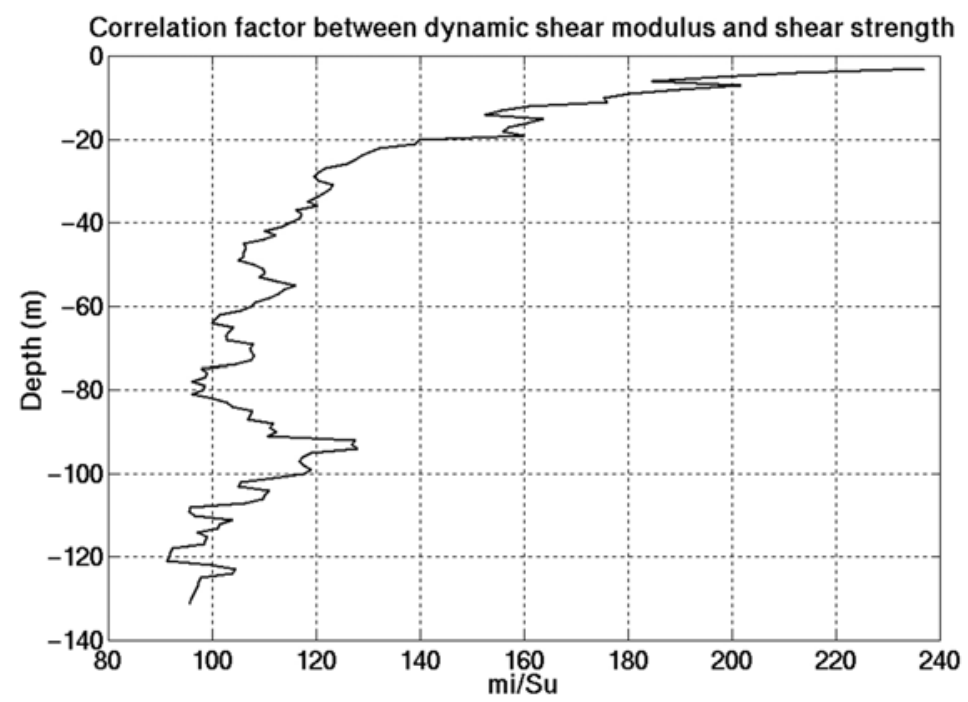

Figure 3 - Correlation factor $f\left(=\mu / S_{U}\right)$. Average from six locations where both $\mu$ and $S_{U}$ were measured in-situ.

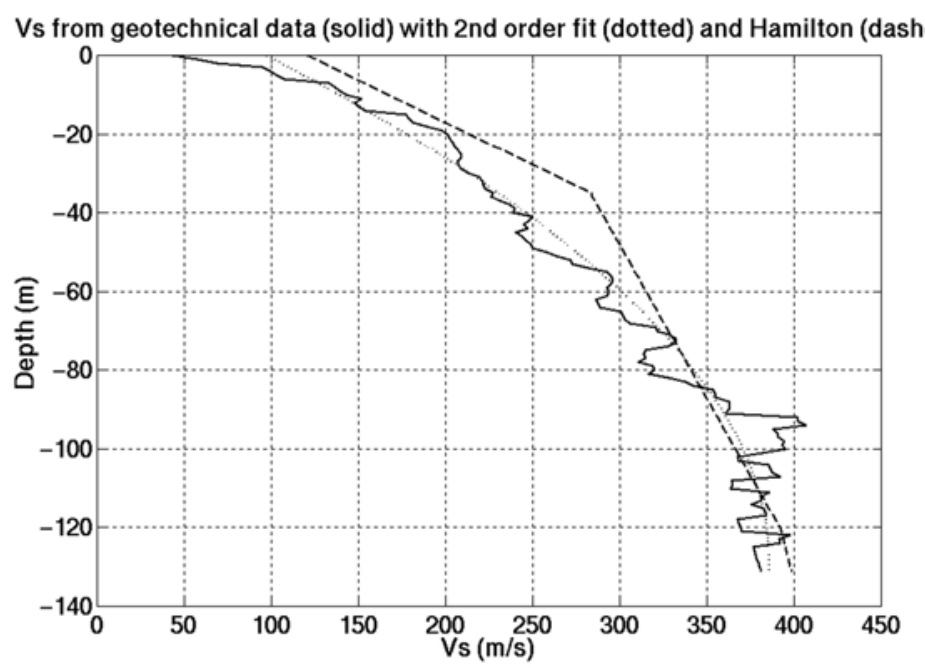

Figure $4-V_{S}$ obtained from Brazilian offshore geotechnical data (continuous line). Also shown for comparison values expected from Hamilton (dashed) and from equation 5 (dotted).

led and processed from Kubena and Post (1992)).

The sea-bottom elastic parameters were obtained by averaging the upper five meters of sediments. A density of 1.05 and $V_{P}$ of $1500 \mathrm{~m} / \mathrm{s}$ were used for the water layer. $V_{p}$ was obtained from Hamilton expressions.

A test was performed to verify if the use of averaging different sediment thickness (10 and $20 \mathrm{~m}$ ) would produce appreciable differences. Figure 5 shows the results. One can conclude the differences are negligible for the P-P mode. For the P-S mode, it can be seen that more shear wave is generated as deeper sediments are considered in the average. This is expected, as a drastic incre- ase in $V_{S}$ occurs in these shallow depths. In Figure 4 , for instance, $V_{S}$ at $20 \mathrm{~m}$ is four times greater than at just below sea floor.

For the reservoir/overburden interface, values normally found in unconsolidated turbidite sandstone of Tertiary age were used (Table 1). It should be pointed that for these reservoirs the P-wave velocity contrast can be much higher than S-wave. Generally, the density contrast is very large and cannot be neglected in modeling studies.

For a downgoing compressional wave, Figure 6 shows that, for most incidence angles commonly present on seismic acquisition, P-P energy is more than 100 times higher than P-S (one 

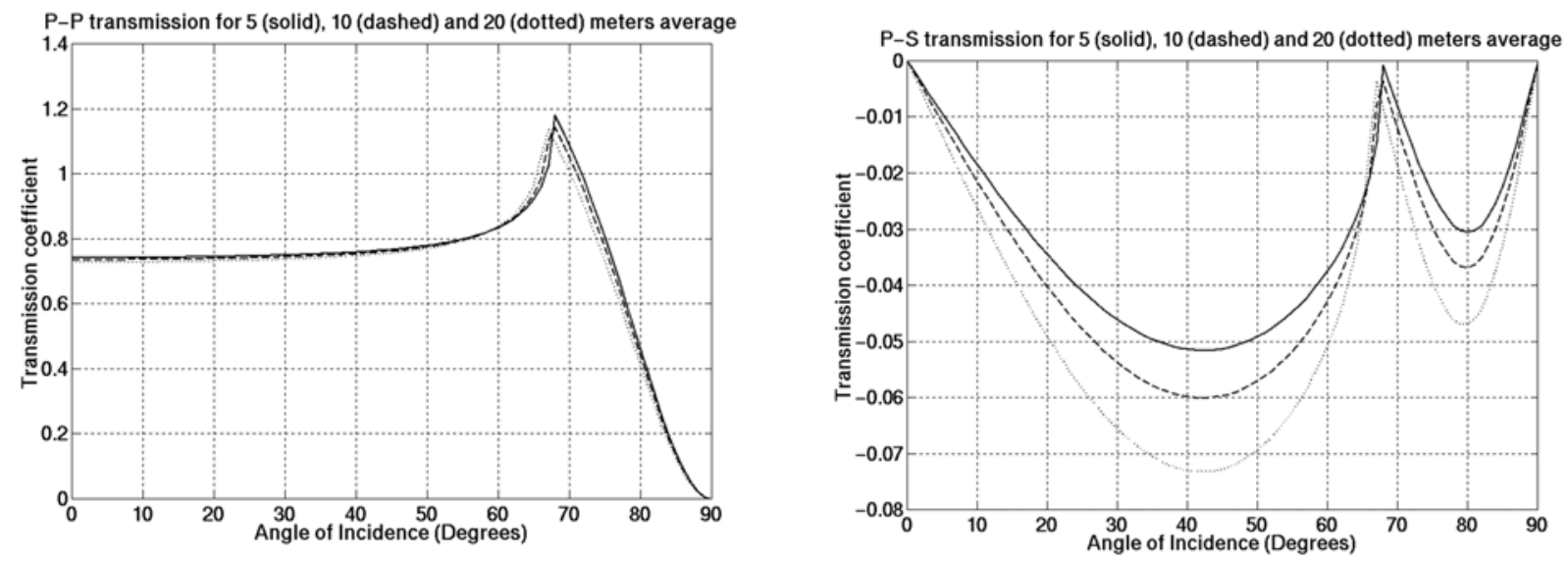

Figure 5 - Transmission coefficient variation at sea-bottom (down-going incident P-wave) for different sediment thickness considered on elastic parameters averaging. P-P (top) and P-S (bottom).

Table 1 - Elastic parameters for reservoir (turbidite) and overburden Tertiary rocks.

\begin{tabular}{|c|c|c|c|}
\hline LAYER & $\begin{array}{c}V_{p} \\
(\mathrm{M} / \mathrm{S})\end{array}$ & $\begin{array}{c}\mathrm{V}_{\mathrm{S}} \\
(\mathrm{M} / \mathrm{S})\end{array}$ & $\begin{array}{c}\text { DENSITY } \\
\left(\mathrm{GM}^{\prime} \mathrm{CM}^{3}\right)\end{array}$ \\
\hline Overburden & 2800 & 1165 & 2.4 \\
\hline Turbidite & 2530 & 1070 & 2.1 \\
\hline
\end{tabular}

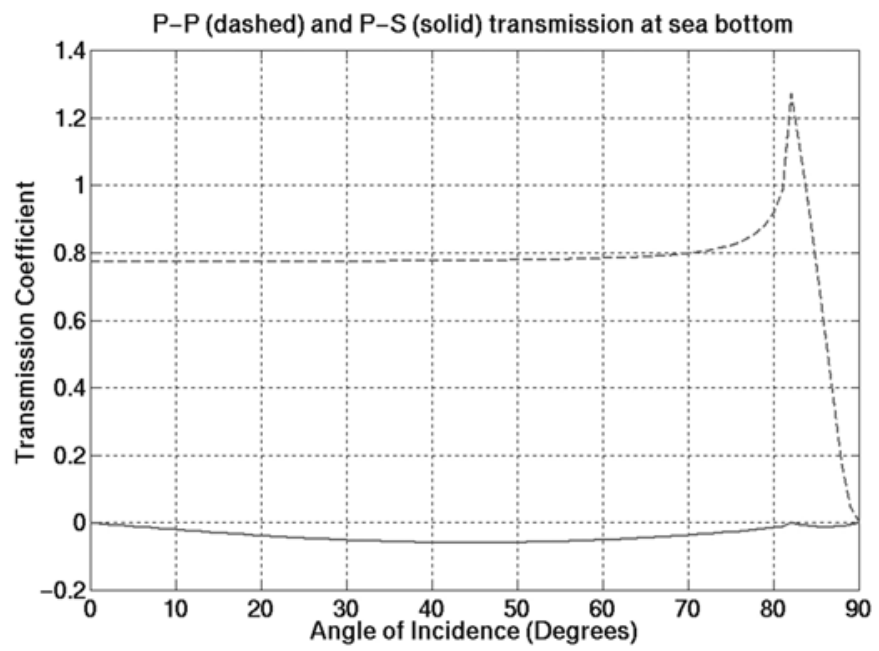

Figure 6 - Transmission coefficients for downgoing P-P (dashed) and P-S (solid) seismic waves in a sea/sediment interface. Energy (proportional to square of amplitude) for P-P is more than 100 times bigger than for $\mathrm{P}-\mathrm{S}$.

should take the square of the amplitude transmission coefficient to analyze energy). This is a strong indication that conversion from P- to S- wave at sea bottom can be expected to be very poor in most marine environments.

Reflection coefficients for incident P- and S- waves at top of a turbidite reservoir are presented on Figure 7. From the figure it can be seen that P-S and S-S modes are of relatively similar values over most angles of incidence. The conclusion is no specific mode seismic energy is dramatically stronger than other for reflections at this interface. 


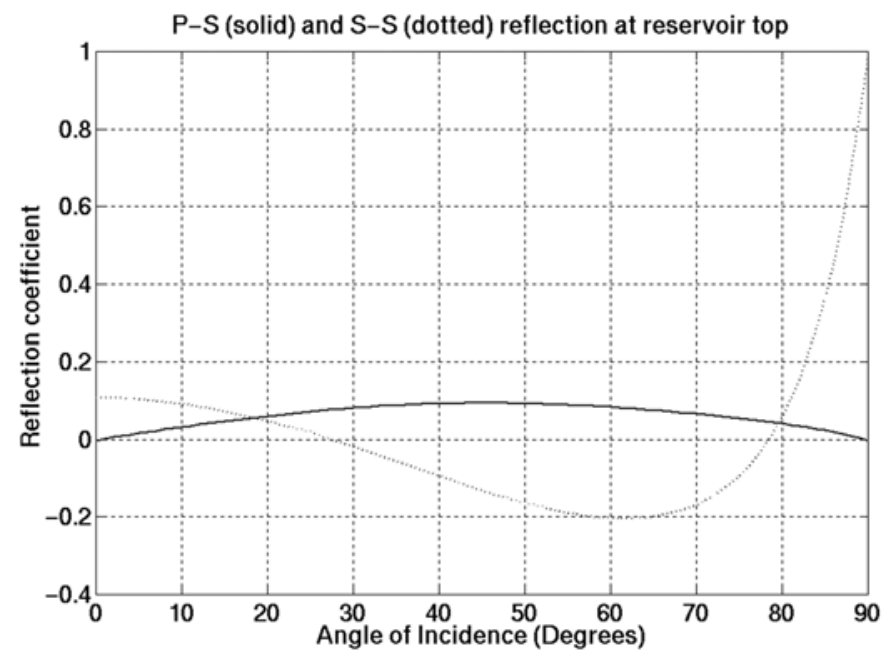

Figure 7 - Reflection coefficient at top of turbidite reservoir for P-S (solid) and S-S (dotted) seismic waves. Up to $40^{\circ}$, modes have (relatively) close reflection coefficient values.

The next analysis step is to multiply the P- to S- transmission coefficient at the sea bottom and the S-S reflection coefficient at the reservoir top and compare the result with the product of P-P transmission coefficient at sea bottom and P-S reflection at reservoir top. In other words, compare amplitudes of PSS and PPS modes.

The results are shown in Figure 8. One can conclude most shear wave energy traveling upward should be created by the PP$S$ mode instead of PS-S mode.

A quantification of how greater PPS mode energy is compared to PSS mode energy is given in Figure 9. The energy was considered equal to the amplitude (from Figure 8) squared. The values of PPS energy over PSS energy were clipped arbitrarily 500 - the ratio values turn very big around $26^{\circ}$ and $80^{\circ}$, because PSS values tend to zero.

One can see from Figure 9 that PPS energy is, in general, over 100 times stronger than PSS energy.

Possible mode conversions (both P-S and S-P) in the upgoing seismic energy were also analyzed. This test, suggested by Prof. Gary Margrave (personal communication), was to verify a possible explanation to a phenomena sometimes seen in OBC data processing (Ebrom et al. (1998); Yuan et al. (1998); Li and Yuan (1999); Rodriguez-Suarez et al. (2000)): the presence of shear-wave energy in the vertical component while the radial component does not present compressional energy. The presence of S-waves in vertical component is verified applying to vertical data the processing flow (e.g., velocities, receiver statics, etc) used in the radial component. A similar procedure - using
P-P processing flow - is used to verify P-P energy in horizontal components.

One should expect, by analyzing Figures 1 and 4, that most up-going shear waves would approach the receivers very close to the vertical, due to the strong decrease in $V_{S}$ at shallow sediments. So, it is somewhat surprising to find P-S energy in the vertical component, mainly when P-P energy is not found in horizontal components.

Margrave's idea was to check if the S-wave energy present in the vertical component could be some compressional energy converted from shear at shallow sediments. If this is the case, the apparent P-P energy will have P-S behavior, regarding velocities, receiver statics and so on.

It should be pointed that the analysis done here is assuming perfectly elastic media. One might argue that very different results could occur if inelastic modeling were used, due to expected very low quality factor for S-waves (QS) in shallow marine sediments. Published data (e.g., Hovem et al. (1991)), however, suggests QS values below 10 are uncommon - in general, $Q_{S}$ equals half $Q_{P}$ in these sediments.

Another assumption is that the elastic parameters values used in this analysis, obtained from offshore Brazil, are representative of most marine sediments lithologies existent in offshore hydrocarbon fields around the world.

The interfaces analyzed for mode conversion were defined based on density discontinuities (Figure 10). Main boundaries were observed at 4, 20, 90 and $160 \mathrm{~m}$ depth.

The resulted transmission coefficients for mode conversion 


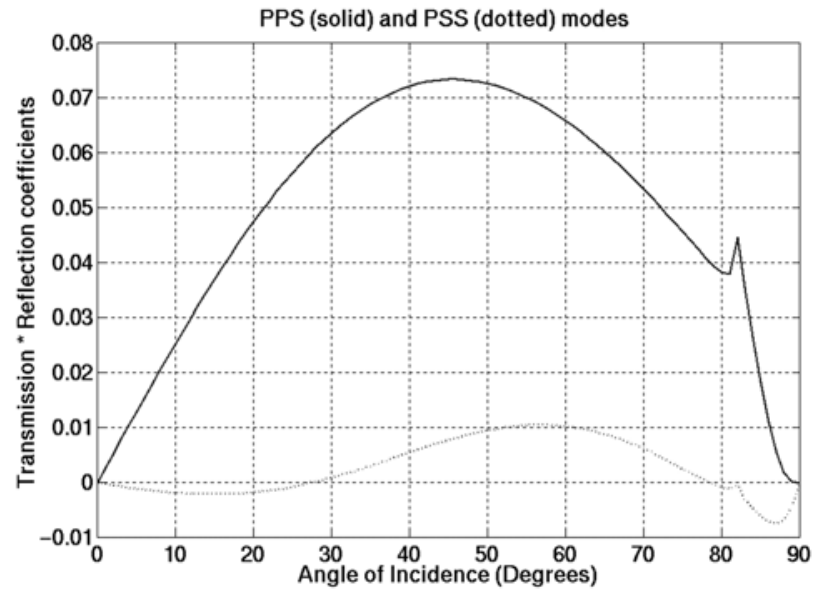

Figure 8 - Amplitude coefficients for PPS mode (P-P transmission at sea bottom and P-S conversion at reservoir top, solid line) and PSS mode (P-S conversion at sea bottom and S-S reflection at reservoir top, dotted line). Clearly, PPS mode has much higher energy than PSS.

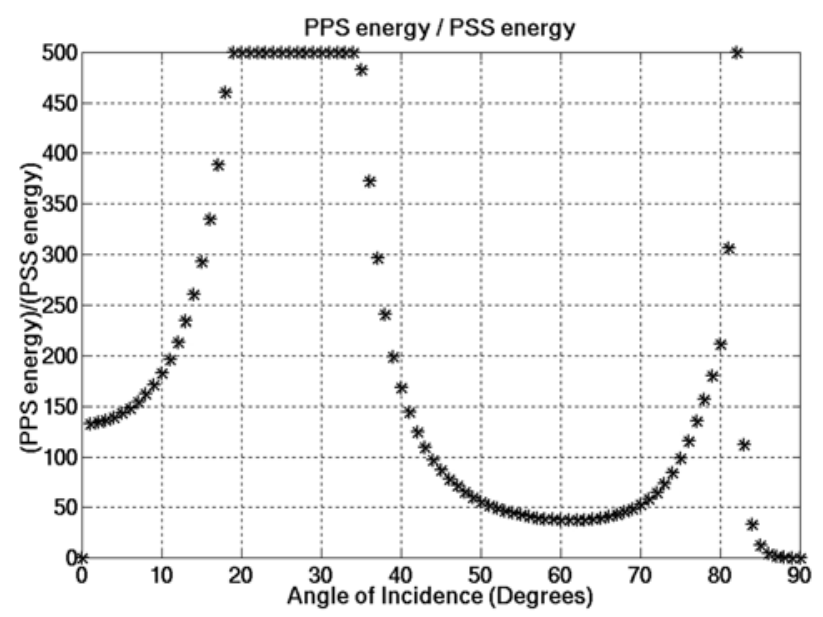

Figure $\mathbf{9}$ - Ratio between PPS energy and PSS energy, clipped to a maximum value of 500 . It is shown that PPS energy is rarely less than 50 times greater than PSS energy, and values over 100 may be expected from most angles used in seismic acquisition.

(P- to S- and S- to P-) of up-going wavefield are shown from Figure 11 to Figure 13.

It is clear in all pictures that the conversion is negligible at all depths, including the sea-bottom, and that most energy transmitted through the interfaces correspond to the same kind of incident energy.

The main conclusion is that an alternative explanation, as for example reflection out of the source-receiver vertical plane, or - more likely - some acquisition problem (e.g., cross-feed), has to be found to explain the presence of P-S energy in vertical geophone component while no P-P energy occurs in horizontal components.

\section{CONCLUSIONS}

Transmission and reflection coefficients for P-and S-wave mode conversion were obtained for the sea bottom and Tertiary hydrocarbon reservoir. Elastic parameters for near-surface marine sediments are calculated using literature data (Hamilton equations) and geotechnical data from offshore Brazil. The geotechnical data showed good agreement with Hamilton's results. A second-order empirical equation to obtain shear-wave velocities as a function of depth for marine sediments is presented.

It is concluded, from previous published data and my results, that most S-wave data recorded in $\mathrm{OBC}$ are related to upcoming conversions at deeper interfaces (PP-S) and not to downgoing 


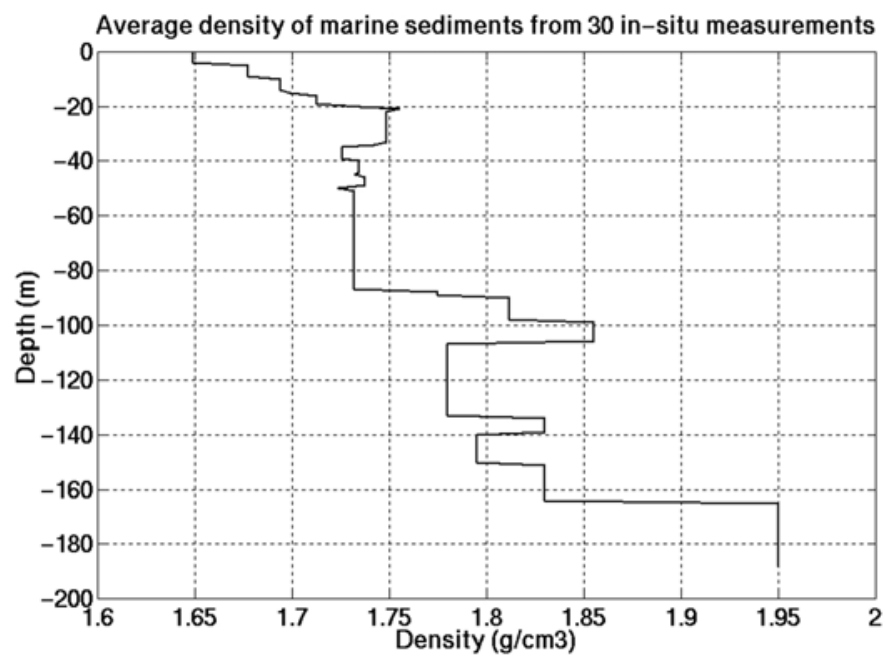

Figure 10 - Average of 30 in-situ measurements of density values for marine sediments. These values were used for $V_{S}$ calculation in this chapter.
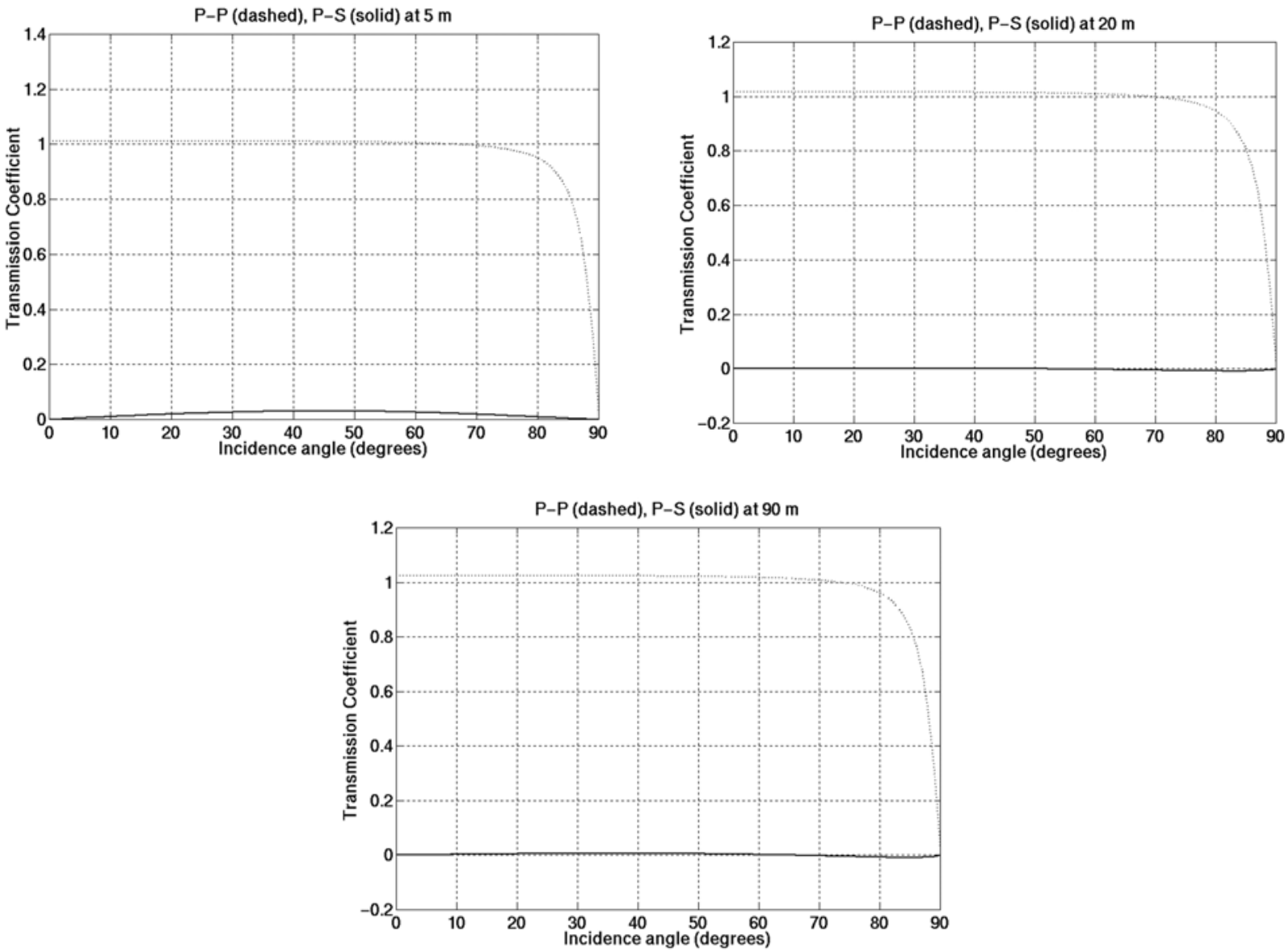

Figure 11 - Transmission coefficients for up-going P-wave (P-P dashed and P-S solid) at (from top to bottom) 5, 20 and $90 \mathrm{~m}$ depth. Most energy does not suffer mode conversion. 

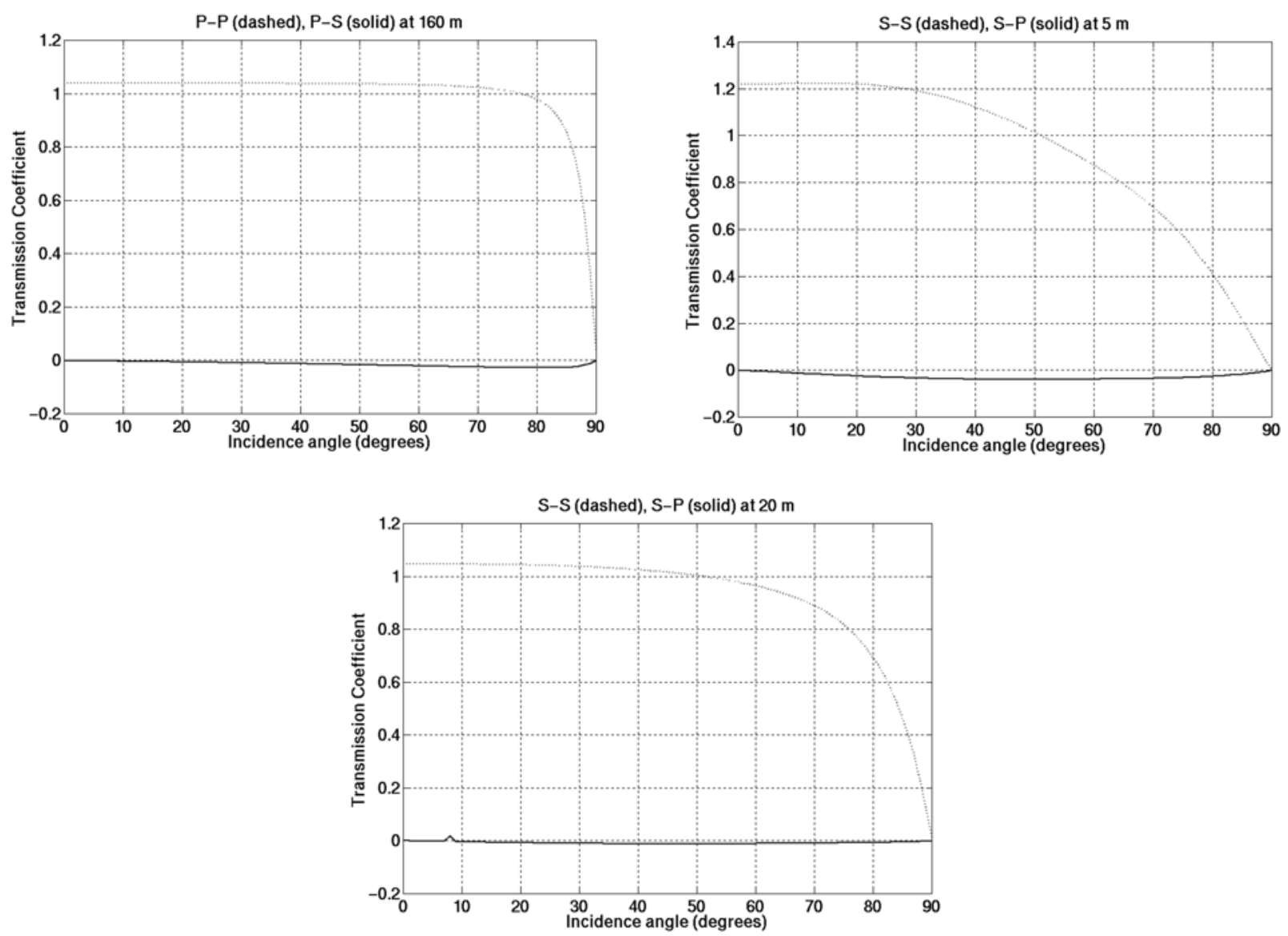

Figure 12 - Transmission coefficients for up-going P-wave (P-P dashed and P-S solid) at $160 \mathrm{~m}$ depth (top) and for up-going S-wave (S-S dashed and S-P solid) at $5 \mathrm{~m}$ (middle) and $20 \mathrm{~m}$ (bottom). Most energy does not suffer mode conversion.

conversions at the ocean bottom (PS-S).

It is also concluded that mode conversion (P- to S- and S- to $\mathrm{P}-$ ) for up-going seismic energy is negligible in shallow marine sediments. This means neither S-wave is expected in vertical nor P-wave on horizontal components.

\section{ACKNOWLEDGMENTS}

I thank Petrobras for the economic support to my research. To Mr. Paulo Roberto Maldonado, from Petrobras, for his help on releasing the geotechnical information from offshore Brazil. I thank my advisor, Prof. Robert Stewart, and Xinxiang Li for their patient and continuous discussion. Appreciation also to Darren Foltinek and Henry Bland for their constant system help, and Prof. Larry Lines and Prof. Gary Margrave for suggestions. To CREWES (University of Calgary) staff and students, for their support. Comments and suggestions by Prof. Paul Stoffa and an anonymous reviewer were greatly appreciated.

\section{REFERENCES}

AMUNDSEN L, ARNTSEN B, KRISTENSEND A, ROGNO H \& SOLLID A. 1999. Multicomponent seabed seismic data: a tool for improved imaging and lithology fluid prediction, Offshore Technology Conference 1999, paper OTC 10939.

AYRES A \& THEILEN F. 1999. Relationship between P- and S-wave velocities and geological properties of near-surface sediments of the continental slope of the Barents Sea: Geophysical Prospecting 47: 431-441.

BALDWIN KC, de ALBA PA \& JONES AN. 1991. Relationship between acoustic and mechanical properties of two marine clays: in Shear Waves in Marine Sediments, ed. J.M. Hovem, pages 95-102. Kluwer Academic Publishers.

BIOT MA. 1956a. Theory of propagation of elastic waves in fluidsaturated porous solid, I: Low-frequency range: Journal of Acoustic Society of America 28: 168-178.

BIOT MA. 1956b. Theory of propagation of elastic waves in fluidsaturated porous solid, II: High-frequency range: Journal of Acoustic Society of America 28: 179-191. 

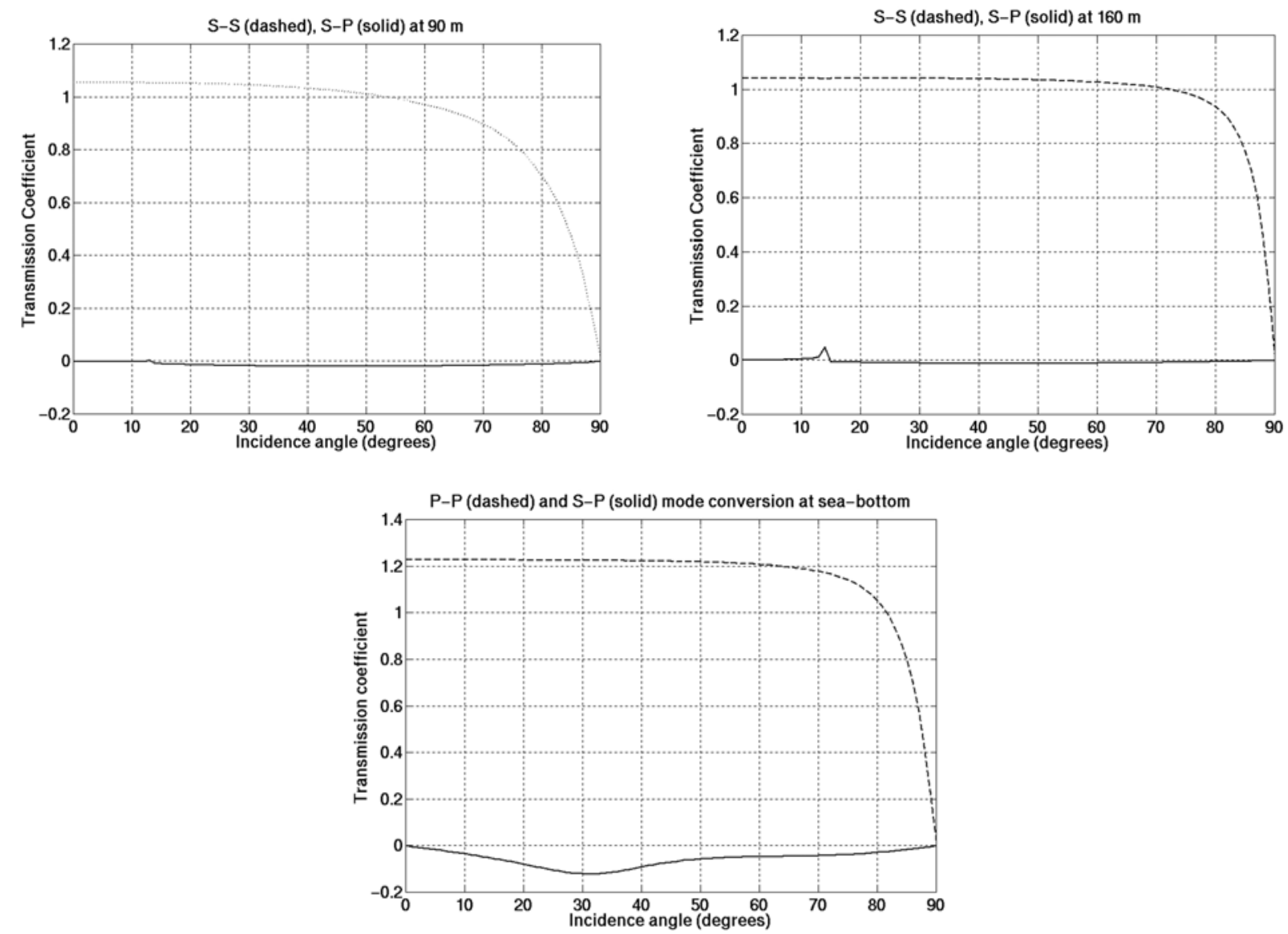

Figure 13 - Transmission coefficients for up-going S-wave (S-S dashed and S-P solid) at $90 \mathrm{~m}$ (top) and $160 \mathrm{~m}$ (middle) and for S- and P-wave up-going at sea-bottom (bottom, P-P dashed, S-P solid). Most energy does not suffer mode conversion.

BREEDING SK, DUNN DA \& ORSI TH. 1991. Shear wave velocities of glacio-marine sediments: Barrents Sea, in: Shear Wave in Marine Sediments, ed. J.M. Hovem et al., pages 149-156. Kluwer Academic Publishers.

BRIGGS KB. 1991. Comparison of measured compressional and shear wave velocity values with predictions from Biot theory: in Shear Wave in Marine Sediments, pages 121-130. Kluwer Academic Publishers.

BRYAN GM \& STOLL RD. 1988. The dynamic shear modulus of marine sediments: J. Acoustical Society America, 83: 2159-2164.

de LANGE G. 1991. Experience with the seismic cone penetrometer in offshore site investigations: in Shear Wave in Marine Sediments, ed. J.M. Hovem et al., pages 275-282. Kluwer Academic Publishers.

DUENNEBIER FK \& SUTTON GH. 1995. Fidelity of ocean bottom seismic observations: Marine Geophysical Researches 17: 535-555.

EBROM D, NOLTE B, PURNELL G, SUKUP D \& KRAIL P. 1998. Analysis of multicomponent seismic data from offshore Gulf of Mexico. $68^{\text {th }}$ Annual Meeting SEG Expanded Abstracts, 162-165.
ESTEVES MGP. 1996. Movimentos de massa: um estudo de integração de dados geológicos, geofísicos, geotécnicos e oceanográficos. M.Sc. Thesis, Universidade Federal Fluminense, Brazil.

HAMILTON EL. 1976. Shear-wave velocity versus depth in marine sediments: a review: Geophysics 41: 985-996.

HAMILTON EL. 1979. Vp/Ns and Poisson's ratio in marine sediments and rocks: Journal Acoustical Society America, 66(4): 1093-1101.

HOVEM JM, RICHARDSON MD \& STOLL RD. 1991. Shear waves in marine sediments. Proceedings of the Conference on Shear Waves in Marine Sediments, La Spezia, Italy, October 15-19, 1990. Kluwer Academic Publishers, 593 pages.

KUBENA ME \& POST ML. 1992. Factual data report on soil investigation, offshore Brazil: PETROBRAS / Fugro-McClelland Engineers B.V. Reports $\mathrm{N}-2850-701, \mathrm{~N}-2850-702, \mathrm{~N}-2850-703, \mathrm{~N}-2850-801$ and N-2850-802. PETROBRAS Internal Reports.

LAVOIE D \& ANDERSON A. 1991. Laboratory measurements of acoustic properties of periplatform carbonate sediments: in Shear Wave in Marine 
Sediments, (ed. by J.M. Hovem et al.), pages 111-120, Kluwer Academic Publishers.

LI X-Y \& YUAN F. 1999. Geophone orientation and coupling in threecomponent sea-floor data: a case study: Geophysical Prospecting, 47(6): 995-1014.

MACELWANE JB \& SOHON FW. 1936. Introduction to Theoretical Seismology, Part I: Geodynamics. John Wiley \& Sons, 366 pages.

MUSKHELISHVILI NI. 1963. Some basic problems of the mathematical theory of elasticity: fundamental equations, plane theory of elasticity, torsion, and bending. Translated from the Russian by J.R.M. Radok. P. Noordhoff (Groningen, Netherlands). 718 pages.

NUR A. 1993. Rock Physics: UNICAMP course notes, São Paulo, Brazil. RICHARDSON MD, MUZI E, MIASCHI B \& TURGUTCAN F. 1991. Shear wave velocity gradients in near-surface marine sediment. In: Shear Waves in Marine Sediments (eds J.M. Hovem et al.), pages 295-304. Kluwer Academic Press.

RICHART FE, HALL Jr. JR \& WOODS RD. 1970. Vibrations of Soils and Foundations, Prentice-Hall, 414 pages.

RICHART FE. 1975. Some effects of dynamic soil properties on soilstructure interaction: Journal of the Geotechnical Engineering Division, ASCE, 101(GT12): 1197-1240.
ROBERTSON PK, CAMPANELLA RG, GILLESPIE D \& RICE A. 1986. Seismic CPT to measure in-situ shear wave velocity: Journal of Geotechnical Engineering, 112(8): 791-803.

RODRIGUEZ-SUAREZ C, STEWART R \& LU H-X. 2000. Analysis of the Teal South, Gulf of Mexico, 3-D 4-C seismic survey, 70th Ann. Internat. Mtg: Soc. of Expl. Geophys., 1150-1153.

SHERIFF RE \& GELDART LP. 1995. Exploration Seismology, $2^{\text {nd }}$ edition, Cambridge University Press, 592 pages.

TATHAM RH \& STOFFA PL. 1976. VPNS - A potential hydrocarbon indicator: Geophysics, 41: 837-849.

TATHAM RH \& McCORMACK MD. 1991. Multicomponent seismology in petroleum exploration: Investigation in Geophysics Series Volume 6, SEG

THEILEN FR \& PECHER A. 1991. Assessment of shear strength of the sea bottom from shear wave velocity measurements on box cores and in-situ: in Shear Wave in Marine Sediments, ed. J.M. Hovem et al., pages 67-74. Kluwer Academic Publishers.

YUAN J, YANG X, ZIOLKOWSKI A \& STRIJBOS F. 1998. Processing 4-C sea-floor seismic data: a case example from the North Sea. 68th Annual Meeting SEG Expanded Abstracts, paper MC1.1, pages 714-717.

\section{NOTES ABOUT THE AUTHOR}

Carlos Rodriguez-Suarez. BSc Geology, 1984, UFRJ; MSc Geophysics, 1987, UFBa/PPPG; Phd Exploration Seismology, 2000, University of Calgary. Areas of interest are acquisition, processing, interpretation, and reservoir characterization of marine seismic data. l've worked in various aspects of these subjects since 1985, first in seismic crew, and then at processing center, followed by exploration and finally exploitation of giant Brazilian offshore oil fields. 